\title{
Contribution of fibreoptic endoscopy to diagnosis and management of children with gastro-oesophageal reflux
}

\author{
P. P. FORGET and M. MERADJI \\ From the Departments of Paediatrics and Paediatric Radiology, Sophia Children's Hospital and Neonatal \\ Unit, and Erasmus University, Rotterdam, The Netherlands
}

\begin{abstract}
Forget, P. P., and Meradji, M. (1976). Archives of Disease in Childhood, 51, 60. Contribution of fibreoptic endoscopy to diagnosis and management of children with gastro-oesophageal reflux. Endoscopic and radiological examination was performed in 53 children with gastro-oesophageal reflux. There was fair agreement between endoscopic and radiological findings. Most patients showed either a normal or an erythematous oesophageal mucosa at endoscopy and these patients became asymptomatic on conservative therapy. 7 children presented destructive changes of the oesophageal mucosa with severe pathological abnormalities. Though their symptoms improved on conservative therapy, 5 required operation because of persistence or deterioration of mucosal damage. Endoscopic and pathological changes returned to normal after operation. Retrospective examination of data led to the definition of 'high risk factors' in this condition.
\end{abstract}

Treatment of gastro-oesophageal reflux in children is still a matter of dispute. Two opposed views exist. While some authors rely mostly on conservative management (Carré, 1960), others firmly advocate surgical treatment of all children where gastroesophageal reflux is associated with a hiatal hernia (Forshall, 1955). These opposing viewpoints are probably best explained by the fear of serious complications, by the difficulty of defining operative indications, and by the variable results of surgical treatment (Forshall, 1955; Burke, 1959; Robb, 1957; Bettex and Kuffer, 1969). Severe oesophagitis is a well-known precursor of peptic stricture of the oesophagus (Sandry, 1972). On these grounds it seems reasonable to treat surgically all patients presenting with severe oesophagitis. A precise diagnosis is therefore of utmost importance. By making routine use of fibreoptic endoscopy, we aimed in the present work at answering the following questions. (1) What are the oesophagoscopic and oesophageal pathological characteristics in children with gastro-oesophageal reflux? (2) What is the value of endoscopic examination as compared to radiological examination in children with gastro-oesophageal reflux ? (3) Does fibreoptic evaluation permit timely selection of 'high risk' patients for operative treatment ?

Received 5 May 1975
(4) Do severe oesophagus pathological lesions revert to normal after operation?

\section{Patients and methods}

Patients. During the past few years gastro-oesophageal reflux was diagnosed in 53 patients in our hospital (patients with oesophageal atresia being excluded). The patients' ages varied from 2 months to 4 years, most of them being younger than one year (mean age 10 months). Of the 53 cases, 33 were boys and 20 were girls. 2 patients were monozygotic, 2 others dizygotic twins. 3 were sisters suffering from gastrooesophageal reflux without hiatal hernia. One patient, operated on for severe oesophagitis associated with gastro-oesophageal reflux and hiatal hernia, had 2 sisters both of whom had been operated on for the same condition. 3 patients had been operated on for pyloric stenosis in the first weeks of life. 2 patients were mentally retarded.

Radiological examination. All children were examined after an 8- to 12-hour fasting period. Depending on their weight, patients were fed $40-80 \mathrm{ml}$ of $50 \%$ barium sulphate suspension. Fluoroscopic examination was started while the child was still drinking. The child was examined for gastro-oesophageal reflux lying supine and in a left oblique position. When no spontaneous reflux occurred compression of the child's stomach by hand was done to see whether gastro-oesophageal reflux could be elicited. Subsequently the patient was examined in a right lateral and supine 
position. Exposures were taken with a 70-minute camera. Duration of fluoroscopy never exceeded 2 minutes.

The intensity of gastro-oesophageal reflux was graded 1 reflux, slight reflux during abdominal compression; grade 2 reflux, massive reflux during abdominal compression; grade 3 reflux, spontaneous reflux. Use was made of criteria described for hiatal hernia (Friedland et al., 1974) in order to diagnose this last condition.

Three radiological signs were considered to be indicative of oesophagitis. These were (1) disturbed oesophageal motility, (2) presence of thickened mucosal folds, and (3) presence of contour irregularities of the oesophagus mucosal lining.

Using these criteria, the presence of oesophagitis was classified as grade 1,2 , or 3 according to the presence of 1,2 , or 3 of these radiological signs. $X$-rays were interpreted by our radiologist who was unaware of endoscopic findings.

Endoscopic examination. All patients were examined after an 8- to 12-hour fasting period with no premedication. The pharynx was sprayed with lignocaine $10 \%$ just before endoscopy. Olympus oesophagofibrescope (model EF type PA) was used for endoscopic examination. The distal end diameter is $7.2 \mathrm{~mm}$, and the instrument could be introduced easily into the oesophagus in all patients. Hiatal hernia was looked for. Biopsies were taken routinely from the distal third portion of the oesophagus.

Treatment. Conservative management consisted of postural therapy, diet therapy, and in most patients Gaviscon powder (Weldon and Robinson, 1972). Postural therapy in small infants was performed by having them sit in an ordinary baby chair day and night. No special attention was given to the angle of the baby's trunk with the horizontal. In older children postural therapy consisted of raising the head of the bed about $15 \mathrm{~cm}$. This therapy was continued for a period of at least one year independent of symptomatic improvement. Diet consisted either of small frequent feeds or of meals given in 2 to 3 portions separated by 10- to 15-minute intervals. Surgical therapy consisted of fundoplication according to Nissen (1961). After therapy patients were considered to be either symtomless or 'improved', improvement occurring when the frequency of vomiting had decreased to less than once a week.

\section{Results}

Oesophageal endoscopic aspects and pathological characteristics. Abnormal findings have consistently been limited to the distal one- to two-thirds of the oesophagus. Endoscopic and pathological findings are shown in Table $I$ and Figs. 1-4. The whitish fibrinous membranes seen at endoscopy in patients with destructive oesophagitis were seen microscopically to originate

\section{TABLE I}

Oesophagus endoscopic aspect and corresponding mucosal pathological findings in children with gastrooesophageal reflux

\begin{tabular}{|c|c|c|}
\hline Terminology used & Endoscopic aspect & Pathology \\
\hline Normal & $\begin{array}{l}\text { Pink coloured } \\
\text { mucosa, smooth } \\
\text { muccsal surface }\end{array}$ & Normal mucosa \\
\hline $\begin{array}{l}\text { Erythematous } \\
\text { oesophagitis }\end{array}$ & $\begin{array}{l}\text { Red coloured } \\
\text { mucosa, smooth } \\
\text { mucosal surface }\end{array}$ & $\begin{array}{l}\text { Normal or minimal } \\
\text { inflammatory } \\
\text { changes }\end{array}$ \\
\hline $\begin{array}{l}\text { Destructive } \\
\text { oesophagitis } \\
\text { (localized or } \\
\text { diffuse) }\end{array}$ & $\begin{array}{l}\text { Destroyed, bleeding } \\
\text { mucosal surface, } \\
\text { locally covered by } \\
\text { whitish } \\
\text { membranes }\end{array}$ & $\begin{array}{l}\text { Granulation tissue, } \\
\text { no recognizable } \\
\text { epithelium }\end{array}$ \\
\hline
\end{tabular}

from ulcerated granulomatous areas. The findings made in our patients are presented in Table II (patients are separated into 2 groups depending on whether or not hiatal hernia was present).

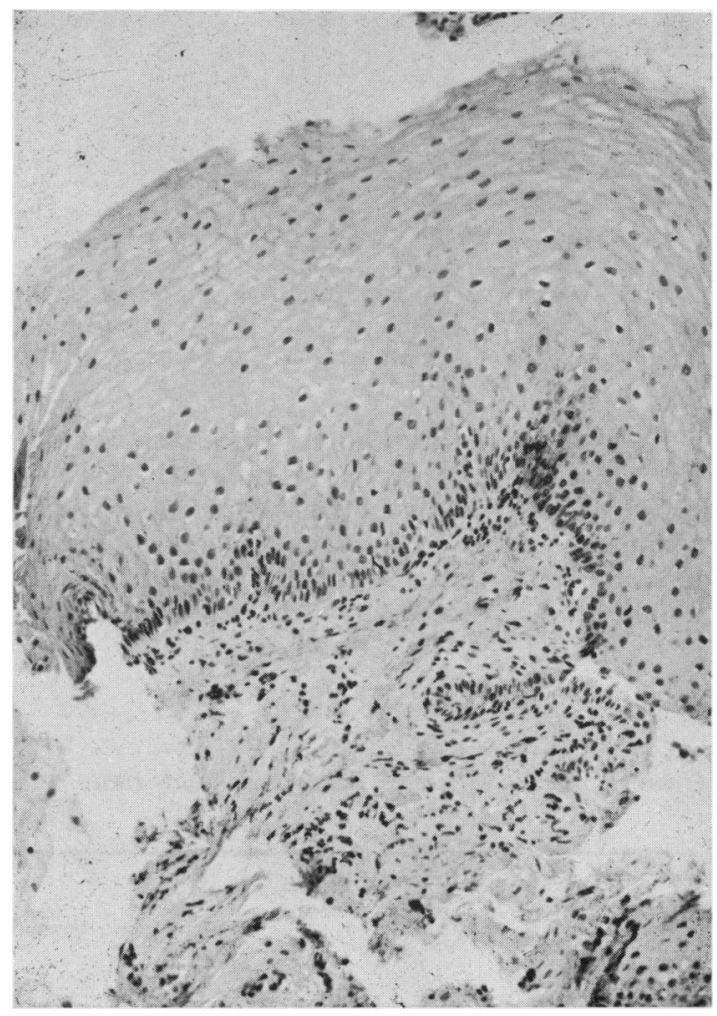

FIG. 1.-Biopsy specimen from a patient showing normal oesophageal mucosa at endoscopy. Sharp distinction between squamous epithelium and lamina propria. No cellular infiltration. $(\times 125$. 


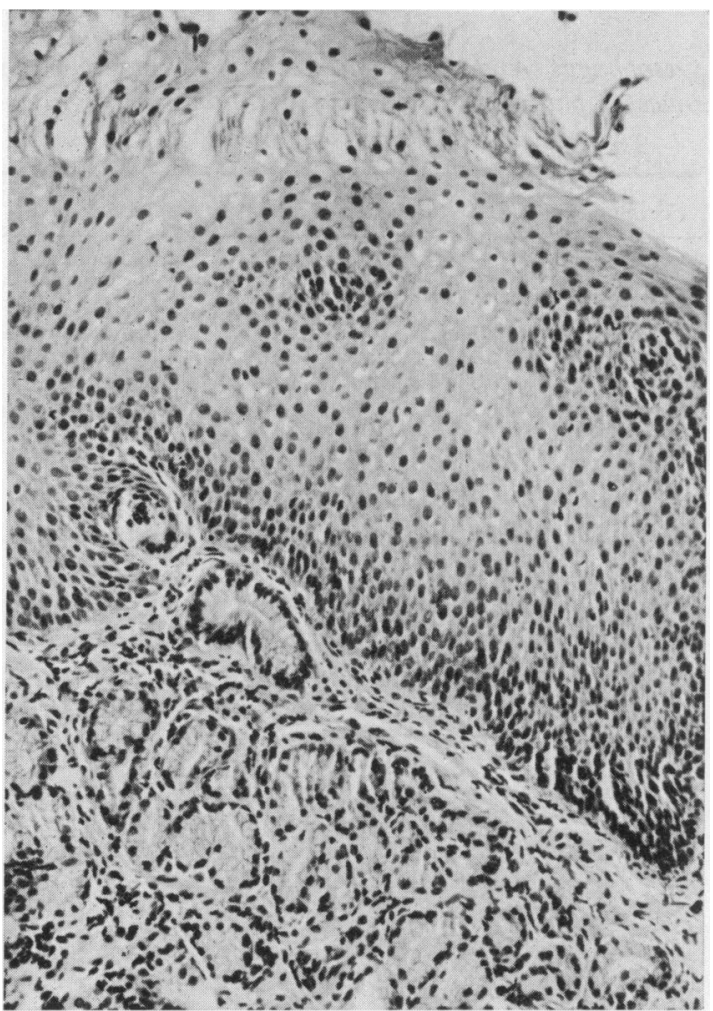

Fig. 2.-Biopsy specimen taken from a patient showing 'erythematous oesophagitis' at endoscopy. Slight cellular infiltration of lamina propria and epithelium. $(\times 320$.

Radiological diagnosis of oesophagitis. Taking endoscopic results as reference, the value radiology in the diagnosis of oesophagitis (see Methods) has been evaluated. Results are shown in Table III. There was fair agreement between radiology and endoscopy in the diagnosis of oesophagitis.
TABLE II

Endoscopic findings in 44 children with gastrooesophageal reflux

\begin{tabular}{l|c|c}
\hline \multicolumn{1}{c|}{ Endoscopic diagnosis } & $\begin{array}{c}\text { Hiatal hernia } \\
(\mathbf{n}=23)\end{array}$ & $\begin{array}{c}\text { No hiatal hernia } \\
(\mathbf{n}=21)\end{array}$ \\
\hline $\begin{array}{l}\text { Normal } \\
\begin{array}{l}\text { Erythematous oesophagitis } \\
\text { Localized destructive } \\
\text { oesophagitis }\end{array}\end{array}$ & 7 & 9 \\
$\begin{array}{l}\text { Diffuse destructive } \\
\text { oesophagitis }\end{array}$ & 3 & 11 \\
\hline
\end{tabular}

* This patient developed a hiatal hernia and diffuse destructive oesophagitis during follow-up period.

Relation between intensity of radiological reflux and presence of oesophagitis. Reflux intensity was evaluated as described under $\mathrm{Me}-$ thods. Results presented in Table IV show that there was a poor correspondence between the intensity of reflux and the presence of oesophagitis, some patients presenting massive gastro-oesophageal reflux without oesophagitis. Still, it can be seen that all patients with destructive oesophagitis had massive gastro-oesophageal reflux.

Endoscopic diagnosis of hiatal hernia. As shown in Table $\mathrm{V}$ hiatal hernia was seen more frequently by radiological than by endoscopic examination.

Follow-up. Follow-up results of medical treatment are presented in Table VI. As it seemed interesting to evaluate separately the effect of medical therapy (see Methods) in those patients with and without destructive oesophagitis our patients were divided into three groups depending on the presence and extent of destructive oesophagitis before medical treatment was started (see Table VI). As shown in the Table most patients with destructive oesophagitis, though definitely

TABLE III

Correspondence between endoscopic and radiological signs of oesophagitis in 45 children with gastro-oesophageal reflux

\begin{tabular}{|c|c|c|c|c|c|}
\hline \multirow[t]{2}{*}{$\begin{array}{l}\text { No. of } \\
\text { patients }\end{array}$} & \multirow[t]{2}{*}{ Endoscopic diagnosis } & \multicolumn{4}{|c|}{$\begin{array}{l}\text { Radiological score } \\
\text { for oesophagitis } \\
\text { (see Methods) }\end{array}$} \\
\hline & & 0 & 1 & 2 & 3 \\
\hline $\begin{array}{r}16 \\
20 \\
4 \\
5\end{array}$ & $\begin{array}{l}\text { No oesophagitis } \\
\text { Erythematous oesophagitis } \\
\text { Localized destructive oesophagitis } \\
\text { Diffuse destructive oesophagitis }\end{array}$ & $\begin{array}{r}14 \\
6 \\
0 \\
0\end{array}$ & $\begin{array}{r}2 \\
13 \\
2 \\
0\end{array}$ & $\begin{array}{l}0 \\
1 \\
1 \\
2\end{array}$ & $\begin{array}{l}0 \\
0 \\
1 \\
3\end{array}$ \\
\hline
\end{tabular}


TABLE IV

Correspondence between presence of oesophagitis at endoscopy and intensity of gastro-oesophageal reflux on $\mathrm{x}$-rays

\begin{tabular}{|c|c|c|c|c|}
\hline \multirow[t]{2}{*}{ No. of patients } & \multirow[t]{2}{*}{ Endoscopic diagnosis } & \multicolumn{3}{|c|}{$\begin{array}{l}\text { Radiological score for gastro-oesophageal reflux } \\
\text { (see Methods) }\end{array}$} \\
\hline & & 1 & 2 & 3 \\
\hline $\begin{array}{r}16 \\
20 \\
4 \\
5\end{array}$ & $\begin{array}{l}\text { No oesophagitis } \\
\text { Erythematous oesophagitis } \\
\text { Localized destructive oesophagitis } \\
\text { Diffuse destructive oesophagitis }\end{array}$ & $\begin{array}{l}5 \\
4 \\
0 \\
0\end{array}$ & $\begin{array}{r}8 \\
12 \\
1 \\
1\end{array}$ & $\begin{array}{l}3 \\
4 \\
3 \\
4\end{array}$ \\
\hline
\end{tabular}

\section{TABLE V}

Correspondence between radiological and endoscopic diagnosis of sliding hiatal hernia in 45 children

\begin{tabular}{l|c|c}
\hline \multirow{2}{*}{ Sliding hiatal hernia } & \multicolumn{2}{|c}{ Diagnosis } \\
\cline { 2 - 3 } & Radiological & Endoscopic \\
\hline Absent & 21 & 26 \\
Present & 24 & 19 \\
\hline
\end{tabular}

improved for variable periods of time by medical therapy, showed progression of oesophageal destruction leading in the end to surgical treatment. Short-term follow-up results of operated patients are presented in Table VIII. In the postoperative period, the presence of oesophagitis could be reliably excluded on $x$-rays in all patients. Therefore, endoscopy was performed in 2 patients only. Most noticeable was the complete reversibility of severe mucosal destruction after operation.

\section{Discussion}

Patients with gastro-oesophageal reflux can be separated into two groups by endoscopic examination. In the first group are patients showing a normal or erythematous oesophagus without mucosal destruction. In the second group are patients presenting mucosal destruction. Most of our patients belonged to the first group. Pathology of biopsies taken from these patients was either unremarkable or showed minimal cellular infiltration. These minimal pathological changes were unreliable for diagnosis. Moreover, it is well known that cellular infiltration of the mucosa is an infrequent finding in patients with symptomatic

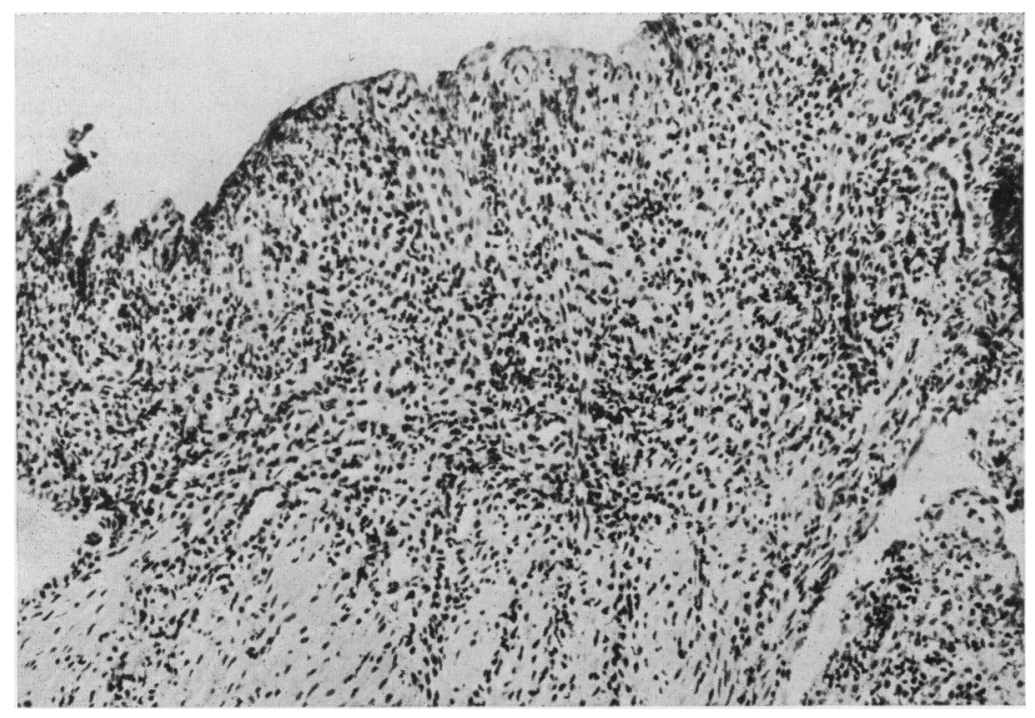

FIG. 3.-Biopsy specimen taken from a patient showing 'destructive oesophagitis' at endoscopy. Granulation tissue without recognizable epithelial structure. $(\times 125$. 


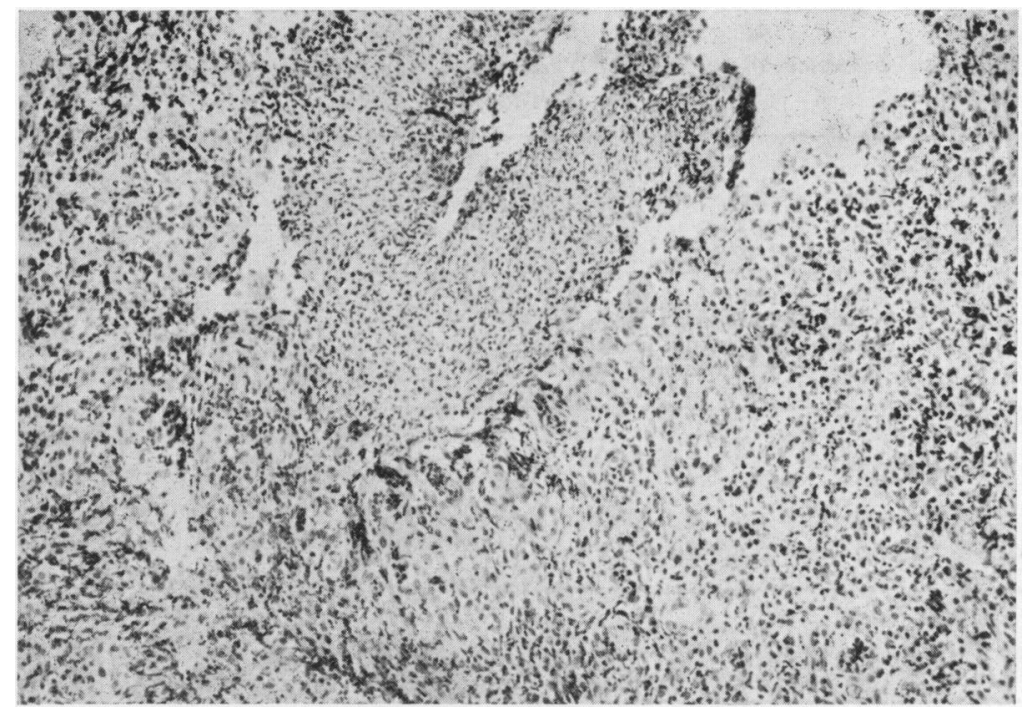

FIG. 4.-Biopsy specimen taken from a patient showing 'destructive membranous oesophagitis' at endoscopy. The ulcerogranulomatous area is covered by a fibrinous membrane. $(\times 125$.

TABLE VI

Short-term follow-up results of medical treatment in 50 patients with gastro-oesophageal reflux

\begin{tabular}{|c|c|c|c|}
\hline Patient & Clinical course & Radiology & Endoscopyt \\
\hline $\begin{array}{l}\text { Group } I(n=43) \\
\text { No destructive oesophagitis } \\
\text { Group } I I(n=4) \\
\text { Localized destructive } \\
\quad \text { oesophagitis } \\
\text { Group III ( } n=3) \\
\text { Diffuse destructive } \\
\text { oesophagitis }\end{array}$ & $\begin{array}{l}40 \text { symptomless within } 6 \mathrm{~m} \\
3 \text { slightly improved } \\
2 \text { symptomless for } 6 \mathrm{~m} \\
1 \text { acute haematemesis } \\
\text { after symptomless period of } 8 \mathrm{~m} \\
1 \text { acute retrosternal pain } \\
\text { after symptomless period of } 12 \mathrm{~m} \\
1 \text { symptomless for } 3 \mathrm{~m} \\
1 \text { improved ( } 1 \mathrm{~m} \text { in hospital) } \\
1 \text { improved ( } 1 \mathrm{~m} \text { in hospital) }\end{array}$ & $\begin{array}{l}5 \text { improved } \\
6 \text { no change } \\
2 \text { no change } \\
\text { Oesophagitis } \\
\text { Oesophagitis } \\
\text { Oesophagitis } \\
\text { and prestenosis }\end{array}$ & $\begin{array}{l}2 \text { no change } \\
\text { Diffuse destructive oesophagitis } \\
\text { Diffuse destructive oesophagitis } \\
\text { Persisting diffuse destructive } \\
\text { oesophagitis and prestenosis } \\
\text { Persisting diffuse destructive } \\
\text { oesophagitis } \\
\text { Persisting diffuse destructive } \\
\text { oesophagitis }\end{array}$ \\
\hline
\end{tabular}

* Radiological control was performed one year after intial diagnosis or when symptoms recurred.

t Endoscopic control was performed when oesophagitis was suspected or in order to evaluate effects of treatment.

TABLE VII

Short-term follow-up of surgical treatment ${ }^{\star}$ in 5 patients with diffuse destructive oesophagitis

\begin{tabular}{|c|c|c|c|c|}
\hline Case no. & Clinical course & Radiologyt & Endoscopic aspect & Oesophagus biopsy \\
\hline $\begin{array}{l}1 \\
2 \\
3 \\
4 \\
5\end{array}$ & $\begin{array}{l}\text { No symptoms } \\
\text { No symptoms } \\
\text { No symptoms } \\
\text { No symptoms } \\
\text { No symptoms }\end{array}$ & $\begin{array}{l}\text { Normal } \\
\text { Normal } \\
\text { Normal } \\
\text { Normal } \\
\text { Hiatal hernia and reflux }\end{array}$ & $\begin{array}{l}\text { Normal } \\
\text { Hiatal hernia, no } \\
\text { oesophagitis }\end{array}$ & $\begin{array}{l}\text { Normal } \\
\text { Normal }\end{array}$ \\
\hline
\end{tabular}

* Fundoplication according to Nissen.

t Radiological and endoscopic control performed approximately 6 months after operation. 
gastro-oesophageal reflux (Sandry, 1972). As suggested in published reports, the endoscopic aspect of patients with slight oesophagitis might correlate better with epithelial changes than with infiltrative changes (Ismail-Beigi, Horton, and Pope, 1970). Though these epithelial changes were evident in some of our patients, most of our biopsies were too small for this pathological diagnosis to be made. Furthermore, much doubt has been cast on the clinical significance of these epithelial changes by a recent paper which shows such changes to be present in approximately $20 \%$ of control patients (Weinstein, Bogoch, and Bowes, 1975). Consequently, our data did not allow us to make a reliable pathological diagnosis of oesophagitis in this first group of patients.

By contrast, very severe pathological changes characterized patients belonging to the second group (mucosal destruction). Though endoscopic examination is the only way to make this diagnosis with certainty, our results show radiology to be a very helpful diagnostic tool (Table III). In order to find whether the clinical history could give any clue as to the presence of destructive oesophagitis, we reviewed retrospectively the clinical data of our patients. The conclusion was that severe, chronic ( $>4$ weeks) haematemesis was the only clinical symptom which when present could be considered indicative of destructive oesophagitis. Other common symptoms and signs of gastrooesophageal reflux were of little help in making this diagnosis.

Our results further show that the presence of a hiatal hernia carries a bad prognosis, as all our patients with diffuse destructive oesophagitis had an associated hiatal hernia. One patient who had a localized destructive oesophagitis without hiatal hernia developed a hiatal hernia and diffuse destructive oesophagitis during the follow-up period.

Table IV shows that only a few patients with massive gastro-oesophageal reflux developed severe oesophagitis. This could be due either to individual variation in oesophageal mucosal resistance to reflux material, or to differences in volume or acidity thereof. It can be seen from Table IV that destructive oesophagitis was never found in patients with grade 1 reflux. Consequently, only the presence of massive gastro-oesophageal reflux should be considered as a 'high risk factor'.

As shown in Table $\mathrm{V}$ hiatal hernia was diagnosed more frequently by radiological than by endoscopic examination. The reason for this could be that, contrary to what happens during radiological examination, abdominal compression is not used during endoscopic examination. Conse- quently, a hiatal hernia which is only detectable during abdominal compression will be missed at endoscopy.

Our follow-up results of medical treatment are similar to those reported by others (Carré, 1960). These results are very satisfactory when one considers that in most of our patients treatment was begun in late infancy and that in such cases poor results of conservative therapy can be expected (Carré, 1960). Carré, contrary to what has been done in this study, made no use of diet therapy, which might partly explain the differences in results. In spite of the fact that most treated patients were asymptomatic, radiological control performed in 13 patients on conservative therapy for one year showed persistence of gastro-oesophageal reflux in all patients. This discrepancy between clinical and radiological evaluation has been reported by other authors (Nusslé, Genton, and Philippe, 1969). The clinical significance of this asymptomatic gastro-oesophageal reflux is not known.

Two of our patients with localized destructive oesophagitis became asymptomatic for 8 and 12 months, respectively, during conservative treatment. Diffuse destructive oesophagitis developed hereafter. One patient with diffuse destructive oesophagitis became asymptomatic on conservative therapy. Control endoscopy 3 months later showed persisting diffuse destructive oesophagitis with 'prestenosis' which was successfully operated. This shows first that the disappearance of symptoms in a patient does not necessarily mean that the patient is 'cured', and secondly that it is probably unwise to stop medical treatment a few weeks after disappearance of symptoms as is usually done. It might be better to pursue medical treatment until control $x$-rays have shown the disappearance of severe gastro-oesophageal reflux.

The last point concerns the timing of operation. Logically patients should be operated on before irreversible pathological changes have occurred. Peptic stricture accompanied by extensive fibrosis is the irreversible end stage of chronic diffuse destructive oesophagitis (Torrance, 1973). On the other hand, pathological changes of acute diffuse destructive oesophagitis were shown to be reversible in our patients only after operation (Table VII). Operative treatment seems therefore imperative in patients with acute diffuse destructive oesophagitis before chronicity leads to irreversible damage. In patients with acute localized destructive oesophagitis, a trial period of conservative therapy seems warranted. If, after a few months, endoscopic control shows no improvement, operation should 
be performed. It appears from this study that though most patients with gastro-oesophageal reflux have a very favourable outcome, some do not. The following should be considered as 'high risk' factors and lead to very careful follow-up: hiatal herniation, massive gastro-oesophageal reflux on $x$-rays, haematemesis, and suspicion of oesophagitis on $x$-ray. Endoscopic examination is mandatory whenever the presence of these high risk factors makes it necessary to exclude the diagnosis of 'destructive oesophagitis'.

\section{REFERENCES}

Bettex, M., and Kuffer, F. (1969). Long-term results of fundoplication in hiatus hernia and cardio-oesophageal chalasia in infants and children. Report of 112 consecutive cases. Fournal of Pediatric Surgery, 4, 526.

Burke, J. B. (1959). Partial thoracic stomach in childhood. British Medical fournal, 2, 787.

Carré, I. J. (1960). Postural treatment of children with a partial thoracic stomach (hiatus hernia). Archives of Disease in Childhood, 35, 569.

Forshall, I. (1955). The cardio-oesophageal syndrome in childhood. Archives of Disease in Childhood, 30, 46.

Friedland, G. W., Dodds, W. J., Sunshine, P., and Zboralske, F. F. (1974). The apparent disparity in incidence of hiatal herniae in infants and children in Britain and the United States. American fournal of Roentgenology, 120, 305.

Ismail-Beigi, F., Horton, P. F., and Pope, C. B. (1970). Histological consequences of gastroesophageal reflux in man. Gastroenterology, 58, 163.

Nissen, R. (1961). Gastropexy and 'fundoplication' in surgical treatment of hiatal hernia. American fournal of Digestive Diseases, 6, 954.

Nusslé, D., Genton, N., and Philippe, P. (1969). Evolution clinique et radiologique des malpositions cardiotubérositaires non opérées de nourrisson. Helvetica Paediatrica Acta, 24, 145.

Robb, D. (1957). Hiatus hernia in infants and children. New Zealand Medical fournal, 56, 238.

Sandry, R. J. (1972). Pathology of reflux esophagitis. Gastrooesophageal Reflux and Hiatal Hernia, p. 43. Ed. by D. B. Skinner, R. H. R. Belsey, T. R. Hendrix, and G. D. Zuidema. Little, Brown, Boston.

Torrance, B. (1973). Symposium on gastro-oesophageal reflux and its complications. Section 6, Surgical treatment. Gut, $14,249$.

Weinstein, W. M., Bogoch, E. R., and Bowes, K. L. (1975). The normal human esophageal mucosa: a histological reappraisal. Gastroenterology, 68, 40.

Weldon, A. P., and Robinson, M. J. (1972). Trial of Gaviscon in the treatment of gastro-oesophageal reflux of infancy. Australian Paediatric fournal, 8, 279.

Correspondence to Dr. P. Forget, Sophia Children's Hospital and Neonatal Unit, Gordelweg 160, Rotterdam, The Netherlands.

The following articles will appear in future issues of this journal:

Two XX males diagnosed in childhood: endocrine, renal, and laboratory findings. B. M. Laurance, C. W. Darby, and M. Vanderschueren-Lodeweyckx.

Phototherapy for hyperbilirubinaemia in very low birthweight infants. M. W. Moncrieff and J. Dunn.

Sick sinus syndrome in children. O. Scott, F.J. Macartney, and P. B. Deverall.

Chorionic somatomammotrophin (hCS) as an index of fetal growth. D. R. MacMillan, R. Hawkins, and R. N. Collier.

Recurrent thrombocytopenic purpura associated with an accessory spleen. I. M. Hann and J. S. Wainscoat. Benign rectal ulceration of unknown origin: an unusual cause of rectal bleeding. $\quad$ E. R. Howard and W. F. Whimster. 